\title{
GFI-1 overexpression promotes cell proliferation and apoptosis resistance in mycosis fungoides by repressing Bax and P21
}

\author{
XIAOGUANG GU ${ }^{1,2}$, YIMENG WANG ${ }^{3}$, CHUNLEI ZHANG $^{3}$ and YONGSHENG LIU ${ }^{1,2}$ \\ ${ }^{1}$ Department of Dermatology and Venerology, Aviation General Hospital; ${ }^{2}$ Institute of Translational Medicine, \\ Chinese Academy of Sciences, Beijing 100012; ${ }^{3}$ Department of Dermatology and \\ Venerology, Peking University Third Hospital, Beijing 100191, P.R. China
}

Received November 21, 2020; Accepted March 10, 2021

DOI: $10.3892 / \mathrm{ol} .2021 .12782$

\begin{abstract}
Mycosis fungoides (MF) is the most common type of cutaneous T-cell lymphoma. The majority of patients with advanced stage MF are resistant to conventional chemotherapy and thus have a poor prognosis. The transcriptional repressor growth factor independence-1 (GFI-1) serves an important role in the development of T-cells. The results of the present study demonstrated that the expression of GFI-1 at different clinical stages of MF was significantly higher compared with benign inflammatory dermatoses, and there was a significant association with disease progression. Gene knockdown of GFI-1 results in the inhibition of Hut-78 cell proliferation and clone formation in vitro, cell cycle arrest and spontaneous apoptosis, upregulation of cell cycle-related P21, as well as the apoptosis-related proteins Bax and Caspase-3, and downregulation of CDK2. Using luciferase assays, and mutational analysis, it was demonstrated that GFI-1 directly regulated the transcription of $P 21$. The results of the present study highlighted a potential molecular therapeutic approach for the treatment of advanced MF.
\end{abstract}

\section{Introduction}

Mycosis fungoides (MF) is the most common type of cutaneous T-cell lymphoma (CTCL), accounting for $\sim 60 \%$ of all CTCL cases (1). The incidence of MF has increased rapidly in recent years and it is now the second most common type of extra-nodal non-Hodgkin lymphoma (2). However, current understanding of MF remains very limited. The course of MF

Correspondence to: Dr Chunlei Zhang, Department of Dermatology and Venerology, Peking University Third Hospital, 49 North Huayuan Road, Haidian, Beijing 100191, P.R. China E-mail: zhangchunleius@163.com

Dr Yongsheng Liu, Department of Dermatology and Venerology, Aviation General Hospital, 3 Anwai Beiyuan Road, Chao Yang, Beijing 100012, P.R. China

E-mail: skinlaser@sina.com

Key words: mycosis fungoides, GFI-1, Hut-78, P21, Bax is insidious, with early-stage patients exhibiting erythema and plaques on the skin (T1/T2 stage) (3). Skin tumors then develop as the disease reaches the advanced stage (T3 stage) (3). In the advanced stage, malignant T-cells may invade peripheral blood and other organs, leading to the development of leukemia MF or Sézary syndrome (4). For patients with early-stage MF, skin-specific treatments, including local application of glucocorticoids, retinoic acid, UVB irradiation and local radiation therapy, tend to achieve more favorable results (5). However, as the disease progresses to the advanced stage, the spread of the lesions affects the surrounding lymph nodes and internal organs. Local treatment can then only relieve the symptoms and treating the disease through systemic chemotherapy is difficult to achieve (6). The 5-year survival rate of Sézary syndrome is only $24 \%$ (7). The lack of effective treatments for advanced MF and Sézary syndrome is largely due to the poor understanding of its pathogenesis.

Growth factor independence-1 (GFI-1) is a nuclear zinc finger protein that serves an important biological function in the occurrence and development of hematopoietic cells and nerve cells $(8,9)$. GFI-1 is required as a transcriptional repressor in several stages of hematopoietic cell development; for example, in the progression from stem cells to precursor cells to differentiated mature lymphocytes and myeloid cells (10). It also serves an important biological role in the development of T-cells, particularly in the differentiation and function of Th2 cells $(9,11)$. Studies have reported that during the development of T-cells, the thymus T-cell precursors endogenously express a certain amount of GFI-1, whereas mature peripheral T-cells do not express any detectable GFI-1. However, antigen stimulation and activation of Erk1/2 cause T-cell activation, leading to upregulation of GFI-1 expression in peripheral mature T-cells, indicating that it serves an important role in the activation of T-cells (12). GFI-1 serves an important role in the differentiation and proliferation of IL-4-mediated Th2 cells, and a retrovirally mediated increase in GIF-1 expression promotes the proliferation of Th2 cells (11). GFI-1 may serve a suppressive role in the formation of hematological tumors; in mouse models, the absence of GFI-1 expression may lead to the development of myeloid leukemia, whereas overexpression of GFI-1 may cause lymphoma. Therefore, depending on the environment in which the cells are located, GFI-1 has tumor-suppressive and tumor-promoting effects (13). 
These studies demonstrate that abnormal expression of GFI-1 serves an important role in the occurrence and development of tumors, but the expression and role of GFI-1 in cutaneous T-cell lymphoma remains unclear.

In the present study, the protein expression of GFI-1 in patients with MF at different clinical stages was first determined by immunohistochemistry. Subsequently, lentivirus-mediated cell transfection was used to specifically knockdown GFI-1 expression. MTS-based cell viability assays and colony formation assays were performed to detect cell proliferation and colony formation in vitro following GFI-1 knockdown. The present study aimed to investigate whether GFI-1 silencing can increase spontaneous apoptosis and induce cell cycle arrest in vitro. Transcriptome analysis was performed to detect the changes in apoptosis and cell cycle-related genes following GFI-1 knockdown. The dual-luciferase reporter assay was performed to determine whether GFI-1 directly regulates the transcription of $\mathrm{P} 21$ in Hut-78 cells.

\section{Materials and methods}

Skin tissue sections of MF and benign inflammatory dermatoses (BIDs). Skin biopsy tissues were fixed with $10 \%$ neutral buffered formalin for $24 \mathrm{~h}$ at room temperature, paraffin-embedded tissue sections $(3 \mu \mathrm{m})$ from 33 patients at different stages of $\mathrm{MF}$ (patch stage $\mathrm{MF}, \mathrm{n}=11$; plaque stage $\mathrm{MF}$, $\mathrm{n}=11$; tumor stage $\mathrm{MF}, \mathrm{n}=11$ ) were obtained from the clinical databases of the Department of Dermatology and Venereology, Peking University Third Hospital and the Department of Dermatology and Venereology, Aviation General Hospital, Beijing, China, with approval from the Clinical Ethics Board of Peking University Third Hospital and Aviation General Hospital. All experiments were performed in accordance with the Declaration of Helsinki. The characteristics of the recruited patients are listed in Table I. The histological diagnosis of MF was confirmed by two independent pathologists according to the clinical and pathological diagnoses criteria published by the International Society of Cutaneous Lymphoma. The age range of the patients was 27-82 years, with a mean age of 46.1 years. and there were 18 males and 15 females. The disease durations ranged between 3 months and 30 years, with a mean duration of 15.8 years. Skin biopsies were also obtained from 11 subjects with BIDs (chronic dermatitis $n=7$, lichen planus $\mathrm{n}=4$ ) and used as controls.

Immunohistochemistry. Paraffin-embedded sections from $33 \mathrm{MF}$ and $11 \mathrm{BID}$ cases were deparaffinized in xylene for $20 \mathrm{~min}$ and rehydrated with decreasing concentrations of ethanol solutions for $5 \mathrm{~min}$ each, then rinsed three times with PBS for $5 \mathrm{~min}$. Next, the sections were incubated in $3 \% \mathrm{H}_{2} \mathrm{O}_{2}$ for $20 \mathrm{~min}$ at $23-26^{\circ} \mathrm{C}$. Following microwaving for antigen retrieval $(15 \mathrm{~min})$, the sections were washed three times with PBS. They were incubated overnight at $4^{\circ} \mathrm{C}$ in a 1:50 dilution of polyclonal rabbit anti-human GFI-1 antibody (cat. no. ab21061; Abcam), and then stained using the goat anti-rabbit/mouse antibody detection kit (cat. no. PV-9000D; OriGene Technologies, Inc.). Following diaminobenzidine treatment, the slides were counterstained with Mayer's hematoxylin $(0.25 \%)$ at room temperature for $10 \mathrm{sec}$. The tissue slides were scanned using NanoZoomer (NanoZoomer-SQ
C13140-01). Positive and negative controls were included with each run of the samples. The percentage of positive cells was assessed under high-power magnification (x400) using an Olympus light microscope, and the mean positive cells of three fields of view was used.

Cell lines and cell culture. The human CTCL Hut-78 cell line (ATCC no. TIB-161) was cultured in RPMI-1640 medium supplemented with $10 \% \mathrm{FBS}, 100 \mathrm{U} / \mathrm{ml}$ penicillin and $0.1 \mathrm{mg} / \mathrm{ml}$ streptomycin (Gibco; Thermo Fisher Scientific, Inc.), and incubated at $37^{\circ} \mathrm{C}$ with $5 \% \mathrm{CO}_{2}$ in a humidified incubator. The peripheral blood cells of 5 patients with benign inflammatory dermatoses (BID) patients were purified by negative selection with monoclonal antibodies directed against granulocytes, B cells by utilizing a Rosette Sep kit (Stemcell Technologies, Inc.). The purity of cells was verified by FACS using fluorescein isothiocyanate-conjugated anti-CD4 antibody (Becton Dickinson Immunocytometry Systems). More than $90 \%$ purity of cells was confirmed by immune phenotyping.

Lentivirus short hairpin RNA (shRNA) vector-mediated gene knockdown. A total of four lentiviral shRNA (SH1-4) vectors were constructed by ligating four different oligo nucleotides encoding shRNAs against GFI-1 to an mU6-MCS-Ubi-EGFP vector (GV118; Shanghai GeneChem Co., Ltd.) between the HpaI and XhoI restriction enzyme sites. The oligonucleotides encoding a scrambled shRNA were used as the control (SH0). All constructs were verified by DNA sequencing, Lentiviruses containing shRNA vectors were packaged and produced by Shanghai GeneChem Co., Ltd. The Lentiviruses containing shRNA vectors were diluted at 1:10 in medium containing polybrene (final concentration, $5 \mathrm{mg} / \mathrm{ml}$ ) in the wells with the cells. Following incubation for $12 \mathrm{~h}$ at $37^{\circ} \mathrm{C}$, the cultures were replenished with fresh medium and maintained for a further $60 \mathrm{~h}$. Lentiviral production and transduction were performed as previously described (14).

Cell viability assay. Cell viability analysis was performed using a Cell Viability Colorimetric assay kit, which is an MTS-based cell viability assay (Promega Corporation), according to the manufacturer's protocol. In brief, the Hut-78 cell lines were cultured in growth factor-free RPMI-1640 medium with $10 \% \mathrm{FBS}$, and were plated into 6 -well plates $\left(2 \times 10^{4}\right.$ cells $/ \mathrm{ml}$ per well) in $2 \mathrm{ml}$ medium and incubated at $37^{\circ} \mathrm{C}$ with $5 \% \mathrm{CO}_{2}$ for $96 \mathrm{~h}$. Every $24 \mathrm{~h}, 100 \mu \mathrm{l}$ cell suspension was transferred to a 96-well plate, $20 \mu 1$ MTS solution was added, and the sample was left for an additional $2 \mathrm{~h}$. The relative cell viability was measured at $490 \mathrm{~nm}$ using a spectrophotometer. Each condition was assessed in triplicate, and biological replicates were repeated twice.

Colony formation assay. Methylcellulose medium (MethoCult CFC; Stemcell Technologies, Inc.) was used to analyze the ability of the cells to form colonies in vitro. Methylcellulose medium allows for the formation of colonies from a single cell in situ to form a clonal colony. In the two lentiviral transfection groups (SH1 and SH2), the untransfected cells (Hut-78), and the scramble shRNA sequence group (SH0), $10^{3}$ cells were counted under an Olympus confocal microscope 
Table I. Characteristics of subjects with MF $(n=33)$.

\begin{tabular}{|c|c|c|c|c|c|c|}
\hline Patient no. & Sex & Age & Disease duration, years ${ }^{a}$ & MF lesion type & Biopsy site & Overall stage \\
\hline 1 & $\mathrm{~F}$ & 27 & 6 & Patch & Left thigh & IB \\
\hline 2 & $\mathrm{M}$ & 42 & 5 & Patch & Right waist & IB \\
\hline 3 & $\mathrm{M}$ & 82 & 2 & Patch & Left thigh & IB \\
\hline 4 & $\mathrm{M}$ & 37 & 26 & Patch & Back & IB \\
\hline 5 & M & 40 & 6 & Patch & Waist & IB \\
\hline 6 & $\mathrm{~F}$ & 58 & $>10$ & Patch & Back & IB \\
\hline 7 & M & 32 & 13 & Patch & Back & IB \\
\hline 8 & $\mathrm{~F}$ & 25 & $>10$ & Patch & Right buttock & IB \\
\hline 9 & $\mathrm{~F}$ & 37 & 13 & Patch & Left waist & IB \\
\hline 10 & M & 28 & 13 & Patch & NA & IB \\
\hline 11 & $\mathrm{M}$ & 68 & 3 & Patch & Thigh & IA \\
\hline 12 & $\mathrm{~F}$ & 58 & $>30$ & Plaque & Left thigh & IIIA \\
\hline 13 & $\mathrm{~F}$ & 30 & 5 & Plaque & trunk & IB \\
\hline 14 & $\mathrm{~F}$ & 42 & 6 & Plaque & Left arm & IB \\
\hline 15 & $\mathrm{~F}$ & 36 & 8 & Plaque & buttock & IIIA \\
\hline 16 & M & 52 & 17 & Plaque & Left buttock & IIIB \\
\hline 17 & $\mathrm{~F}$ & 64 & 2 & Plaque & Right arm & IIA \\
\hline 18 & M & 74 & 3 months & Plaque & Hack & IA \\
\hline 19 & M & 52 & 7 & Plaque & Trunk & IIA \\
\hline 20 & $\mathrm{~F}$ & 45 & $>30$ & Plaque & Left waist & IIIB \\
\hline 21 & $\mathrm{~F}$ & 44 & 13 & Plaque & Right back & IIA \\
\hline 22 & $\mathrm{~F}$ & 37 & $>10$ & Plaque & Back & IA \\
\hline 23 & M & 35 & 3 & Tumor & Left arm & II \\
\hline 24 & $\mathrm{~F}$ & 44 & 13 & Tumor & Back & IIA \\
\hline 25 & M & 30 & 7 & Tumor & Left waist & II \\
\hline 26 & $\mathrm{M}$ & 61 & 3 & Tumor & NA & IVA \\
\hline 27 & M & 47 & 15 & Tumor & Left waist & II \\
\hline 28 & $\mathrm{~F}$ & 54 & 13 & Tumor & Back & IIA \\
\hline 29 & $\mathrm{~F}$ & 44 & 13 & Tumor & Right back & IIA \\
\hline 30 & M & 58 & 3 & Tumor & Right back & IVA \\
\hline 31 & M & 58 & 2 & Tumor & Right neck & II \\
\hline 32 & $\mathrm{M}$ & 28 & 7 & Tumor & Chest & IIB \\
\hline 33 & M & 52 & 8 & Tumor & Right buttock & II \\
\hline
\end{tabular}

F, female; M, male; MF, mycosis fungoides; NA, not available. ${ }^{a}$ Unless otherwise stated.

(magnification, x200). Cells were added to the methylcellulose medium and shaken. A syringe with a blunt-tip needle was then used to inoculate the mixed cells into a petri dish, where they were cultured at $37^{\circ} \mathrm{C}$ with $5 \% \mathrm{CO}_{2}$ for 14 days. Cells were then counted and colony types evaluated using an inverted microscope $(\mathrm{x} 200)$ and a grid counting dish. The experiment was repeated three times and the mean calculated.

Cell cycle and apoptosis analysis using flow cytometry. For the analysis of spontaneous apoptosis, the cells in the lentiviral transfection groups ( $\mathrm{SH} 1$ and $\mathrm{SH} 2$ ), the untransfected group (Hut-78), and the scrambled shRNA sequence group (SH0) were seeded at $4 \times 10^{5} / \mathrm{ml}$ in $2 \mathrm{ml}$ RPMI-1640 medium for $24 \mathrm{~h}$, prior to the cells being washed with cold PBS and fixed in cold $70 \%$ ethanol overnight at $-20^{\circ} \mathrm{C}$. Next, the cells were suspended in $100 \mu \mathrm{l}$ PBS, and then stained with
$5 \mu 1$ 7-aminoactinomycin $\mathrm{D}$ and $5 \mu 1$ phycoerythrin-conjugated Annexin V using the Annexin V-PE Detection kit I (BD Pharmingen) at room temperature for $15 \mathrm{~min}$, and quantified by flow cytometric analysis on a FACScan flow cytometer (BD Biosciences). Cell cycle analysis was performed using PI-mediated flow cytometry. A total of $5 \times 10^{5}$ transfected cells (SH1 and SH2), as well as control cells (Hut-78 and SH0) were collected, fixed and permeabilized with $100 \%$ ethanol for $1 \mathrm{~h}$ at $4^{\circ} \mathrm{C}$. Following treatment with DNase-free RNase, the cells were stained with $50 \mu \mathrm{g} / \mathrm{ml}$ PI for $1 \mathrm{~h}$ at room temperature. Distribution of the cell-cycle phases was determined using a FACScan flow cytometer (BD Pharmingen). For each sample, 10,000 gated events were obtained. Flow cytometry data were analyzed using CellQuest Pro and ModFit v3.3 software (BD Biosciences). The experiments were performed in triplicate and repeated at least three times. 
Gene expression profile analysis. Total RNA was extracted from cells using TRIzol ${ }^{\circledR}$ reagent (Invitrogen; Thermo Fisher Scientific, Inc.), purified and reverse-transcribed into cDNA using the Reverse Transcription System (Promega Corporation). The reaction steps were as follows: Add $2 \mu \mathrm{l}$ of total RNA to the RT system to control the total reaction system to $20 \mu \mathrm{l}$. The RT reaction conditions were as follows: $42^{\circ} \mathrm{C}$ for $15 \mathrm{~min}, 95^{\circ} \mathrm{C}$ for $5 \mathrm{~min}$ and $4^{\circ} \mathrm{C}$ for $5 \mathrm{~min}$. Hybridization of the cDNA library was performed on Whole Human Genome Oligo microarrays (cat. no. G4112F; Agilent Technologies, Inc.). Agilent microarray slides were scanned using the Agilent DNA Microarray Scanner (Agilent Technologies, Inc.). Hybridization signals were normalized and analyzed using GeneSpring software version 7.3 to identify significantly differentially expressed genes.

Western blot analysis. Cell lysates were prepared using RIPA lysis and extraction buffer (cat. no. 89900; Thermo Fisher Scientific, Inc.), and the concentrations were quantified using a BCA assay. Protein lysates were then separated on NuPAGE Novex Bis-Tris Gels (Invitrogen; Thermo Fisher Scientific, Inc.). A total of $40 \mu \mathrm{g}$ protein/lane was separated by $12 \%$ SDS-PAGE. The separated proteins were subsequently transferred onto nitrocellulose membranes and blocked with 1xTris buffered saline containing Tween-20 and $2.5 \%$ skimmed milk at $25^{\circ} \mathrm{C}$ for $1 \mathrm{~h}$. The membranes were incubated with the following primary antibodies: Rabbit anti-GFI-1 antibody (1:500; cat. no. ab21061; Abcam), rabbit anti-Bax antibody (1:1,000; cat. no. Ab32503; Abcam), monoclonal rabbit anti-pro-caspase3 antibody (1:1,000; cat. no. Ab32150; Abcam), monoclonal rabbit anti-cleaved-caspase 3 antibody (1:500; cat.no. Ab32042; Abcam), monoclonal rabbit anti-P21 antibody (1:1,000; cat. no. Ab109199; Abcam), monoclonal rabbit anti-CDK2 antibody $(1: 1,000$; cat. no. Ab32147; Abcam), monoclonal rabbit anti-GAPDH antibody (1:2,000; cat. no. Ab8245; Abcam) and monoclonal mouse anti- $\beta$-Actin antibody $(1: 2,000$; cat. no. Ab32150; Abcam), overnight at $4^{\circ} \mathrm{C}$ and rinsed with 1xTBST 3 times for 5 min each. Following the primary incubation, membranes were incubated with 1:10,000 HRP labeled Goat anti-Mouse antibody (cat. no. G-21040; Thermo Fisher Scientific, Inc.), 1:10,000 HRP labeled Goat anti-Rabbit antibody (cat. no. G-21234; Thermo Fisher Scientific, Inc.), for $1 \mathrm{~h}$ at $25^{\circ} \mathrm{C}$, subsequently washed with TBST and imaged on a LI-COR Odyssey ${ }^{\circledR}$ Imaging System. Relative protein expression was determined using ImageQuant version 5.2 software (Molecular Dynamics).

$R T-q P C R$. Total RNA was extracted from aliquots of cells using TRIzol ${ }^{\circledR}$ Reagent (Invitrogen; Thermo Fisher Scientific, Inc.), according to the manufacturer's protocol. and RT reactions were performed as previously described $(15,16)$. qPCR was performed according to our previous study (17), Reaction conditions were as follows: Denaturation at $95^{\circ} \mathrm{C}$ for $10 \mathrm{~min}$; then denaturation at $95^{\circ} \mathrm{C}$ for $15 \mathrm{~s}$ and annealing at $60^{\circ} \mathrm{C}$ for 1 min repeat 40 cycles. Real time PCR dissociation curve: $95^{\circ} \mathrm{C}$ foe $15 \mathrm{sec}, 60^{\circ} \mathrm{C}$ for $1 \mathrm{~min}$ and $95^{\circ} \mathrm{C}$ for $15 \mathrm{sec}$. Quantification of gene expression was performed using a 7500 Real Time PCR system (Applied Biosystems; Thermo Fisher Scientific, Inc.) with $G A P D H$ as the internal control. The results are presented as copies of the specific genes per 10,000 copies of GAPDH. The sequences of the primers were as follows: GFI-1 forward, 5'-GCCCTACCCCTGTCAGTACTGT-3' and reverse, 5'-CAC
CAGTGTGGATGAAAGTGTGT-3'; P21 forward, 5'-GGC AGACCAGCATGACAGATT-3' and reverse, 5'-TTCCTG TGGGCGGATTAGG-3'; CDK2 forward, 5'-TAAAGTTGT ACCTCCCCTGGATGA-3' and reverse 5'-AAATCCGCT TGTTAGGGTCGTA-3'; Bax forward, 5'-ACCAAGAAGCTG AGCGAATGT-3' and reverse, 5'-CAGATGGTGAGTGAC GCAGTAAG-3'; Caspase-3 forward 5'-GCAAACCTCAGG GAAACATT-3' and reverse, 5'-TTTTCAGGTCAACAGGTC CA-3'; and GAPDH forward, 5'-AAGATCATCAGCAATGCC TCC-3' and reverse, 5'-TGGACTGTGGTCATGAGTCCTT-3'.

Luciferase reporter assay. The wild-type $P 21$ promoter of Hut-78 cell genome (from base pair 1,122 to +247 relative to the transcription start site) was amplified by PCR. The mutated $P 21$ promoter was generated by introducing point mutations to the key nucleotides in the GFI- 1 binding motif using the Fast Mutagenesis system kit (Beijing Transgen Biotech Co., Ltd.), according to the manufacturer's protocol. Wild-type and the mutated promoter were cloned into the pGL3-Basic luciferase vector (Promega Corporation) between the $M l u \mathrm{I}$ and $B g l \mathrm{II}$ restriction enzyme sites by $M l u \mathrm{I}, B g l \mathrm{II}$ restriction enzyme and T4 DNA Ligase (NEB, Inc.), separately. Hut-78 cells were introduced into cells by electroporation using the dual-luciferase reporter assay system (Promega Corporation), according to the manufacturer's protocol. Entranster ${ }^{\mathrm{TM}}-\mathrm{E}$ (Engreen Biosystem Co, Ltd.) was used to improve electrotransfection efficiency. Cells were cultured for $48 \mathrm{~h}$ after transfection for luciferase activity measurement, Relative luciferase activity was quantified by normalization to Renilla luciferase activity, which served as an internal control for transfection efficiency.

Statistical analysis. Statistical analysis was performed using SPSS version 21.0 (IBM Corp.). A Fisher's exact test was used to compare GFI-1 antibody staining amongst the BID group and the different stages of MF. A non-parametric Mann-Whitney U test was used to compare the difference between GFI-1-knockdown clonal cells and control cells. $\mathrm{P}<0.05$ was considered to indicate a statistically significant difference.

\section{Results}

GFI-1 protein expression is significantly higher in patients with CTCL compared with patients with BID. In order to study the expression levels and localization of GFI-1 protein in CTCL, paraffin-embedded sections from 11 cases each of patch, plaque and tumor stage MF were obtained, and immunohistochemical analysis of GFI-1 protein was performed and compared with 11 cases of BID. Representative images of immunohistochemical analysis are presented in Fig. 1. All MF tissues exhibited nuclear staining for GFI-1 protein, with different ratios of infiltrating lymphocytes. The results of the quantitative analysis are presented in Table II; 7 out of 11 (63.6\%) patch stage MF specimens, and all plaque and tumor stage MF specimens demonstrated diffuse nuclear staining of GFI-1 protein in $>25 \%$ of the lymphocytic nuclei, whereas only 1 of $11(9.1 \%)$ BID sections exhibited $>25 \%$ positive staining. There was a significant difference between all MF tissue specimens and BID specimens $(\mathrm{P}<0.05$; Fisher's exact test), and there was also a significant difference between patch stage MF and BID specimens $(\mathrm{P}=0.02$; Fisher's exact test $)$. Further analysis 
Table II. GF1-1 protein expression in different stages of mycosis fungoides.

\begin{tabular}{lcccc}
\hline & \multicolumn{4}{c}{ Percentage of nuclei expressing GF1-1 } \\
\cline { 2 - 4 } Diagnosis & $0-25 \%$ & $26-50 \%$ & $51-90 \%$ & $>90 \%$ \\
\hline Patch stage $(\mathrm{n}=11)$ & $4^{\mathrm{a}}(36.4)^{\mathrm{b}}$ & $6(54.5)$ & $1(9.1)$ & $0(0)$ \\
Plaque stage $(\mathrm{n}=11)$ & $0(0)$ & $5(45.5)$ & $2(18.2)$ & $4(36.4)$ \\
Tumor stage $(\mathrm{n}=11)$ & $0(0)$ & $0(0)$ & $5(45.5)$ & $6(54.5)$ \\
BID $(\mathrm{n}=11)$ & $10(90.9)$ & $1(9.1)$ & $0(0)$ & $0(0)$
\end{tabular}

GFI-1, growth factor independence-1; BID, benign inflammatory dermatoses. ${ }^{a}$ No. cases within the group. ${ }^{b}$ Percentage of cases within the given mycosis fungoides stage.
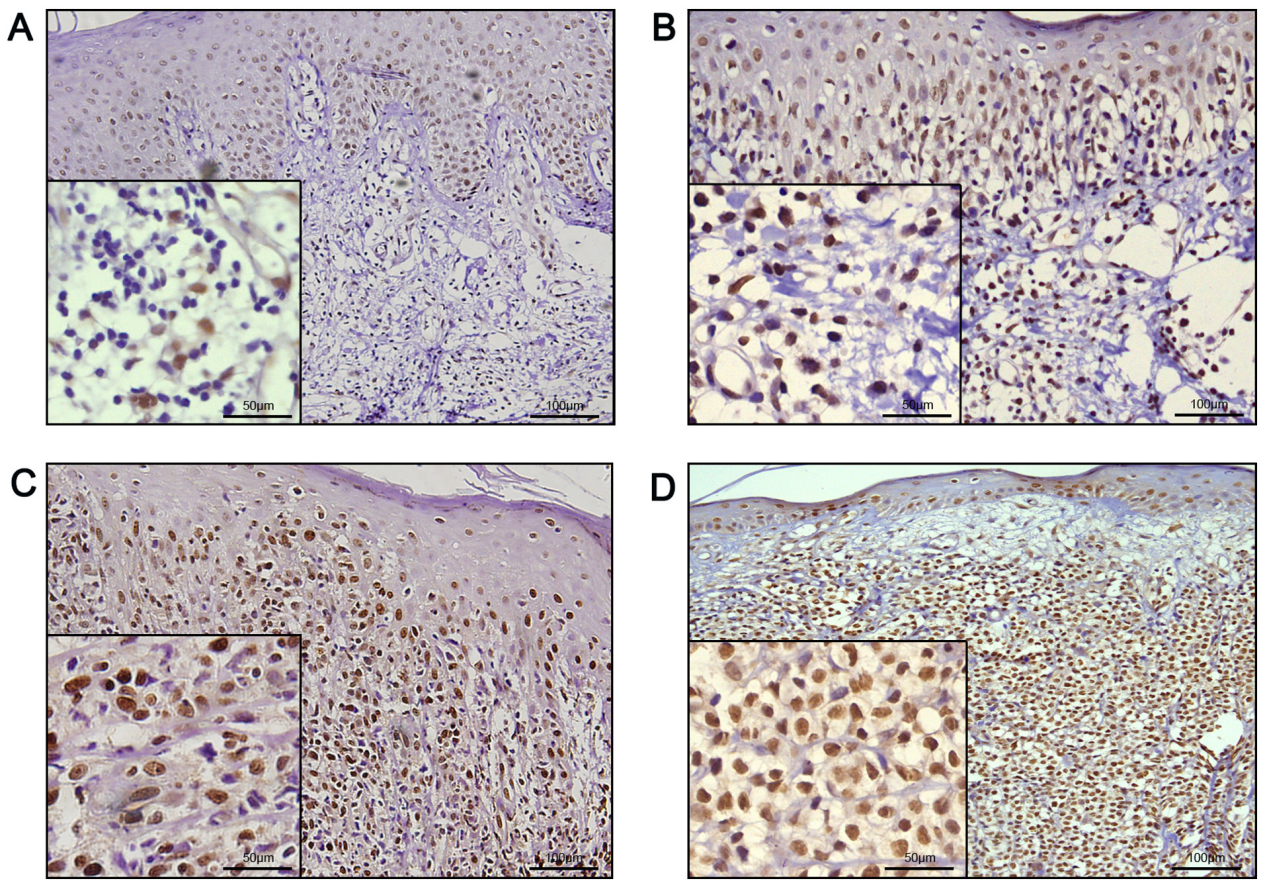

Figure 1. Expression of GFI-1 protein in different stages of MF lesions and benign inflammatory dermatoses. (A) Chronic dermatitis. The majority of the infiltrating lymphocytes were negative, and only a few infiltrating lymphocytes exhibited positive expression. (B) Patch stage MF. Positive expression of GFI-1 protein in the majority of epidermal-lymphocytes. (C) Plaque stage MF and (D) tumor stage MF. The majority of infiltrating atypical lymphocytes exhibited strong positive GFI-1 staining. Magnification, 200x; inset sections, 400x. GFI-1, growth factor independence-1; MF, mycosis fungoides.

demonstrated that in 1 of $11(9.1 \%)$ cases with patch stage MF, 7 of $11(63.6 \%)$ cases with plaque stage MF, and in all the cases of tumor stage MF, GFI-1 protein expression was positive in $>50 \%$ of infiltrating lymphocyte nuclei. There was a significant difference between the patch stage MF and plaque stage MF specimens ( $\mathrm{P}=0.02$; Fisher's exact test), and between the plaque stage $\mathrm{MF}$ and tumor stage MF specimens $(\mathrm{P}=0.04$; Fisher's exact test), suggesting that the expression of GFI-1 protein gradually increased with the progression of the disease.

GFI-1 mRNA expression in MF tissues is significantly higher than that in inflammatory tissues. The GFI-1 mRNA expression levels on fresh skin lesions biopsies from $7 \mathrm{MF}$ patients and 10 fresh skin lesions biopsies from patients with BID were analyzed. GFI-1 mRNA levels in MF were significantly higher than that of BID (Fig. 2). There was a significant difference between patch stage MF and BID $(\mathrm{P}<0.05)$.

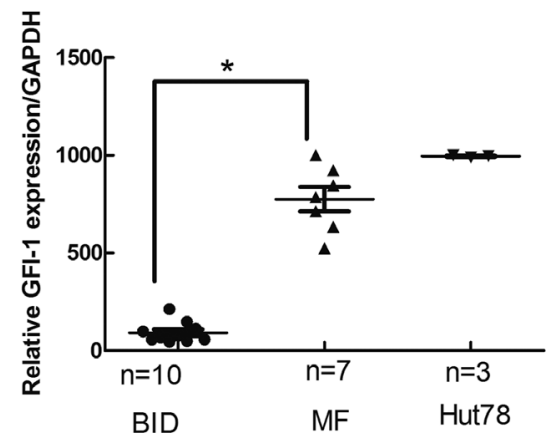

Figure 2. Expression of GFI-1 mRNA in MF lesions and BIDs. Upregulation of GFI-1 mRNA expression in MF lesions. Reverse transcription-quantitative polymerase chain reaction analysis revealed significant upregulation of GFI-1 mRNA expression in lesional skin biopsies of MF $(\mathrm{n}=7)$, compared with benign inflammatory dermatoses $(n=10)$. ${ }^{*} P<0.05$. The relative transcript levels are expressed as copies of GFI-1 per 10,000 copies of GAPDH transcripts. GFI-1, growth factor independence-1; MF, mycosis fungoides; BIDs, benign inflammatory dermatoses. 

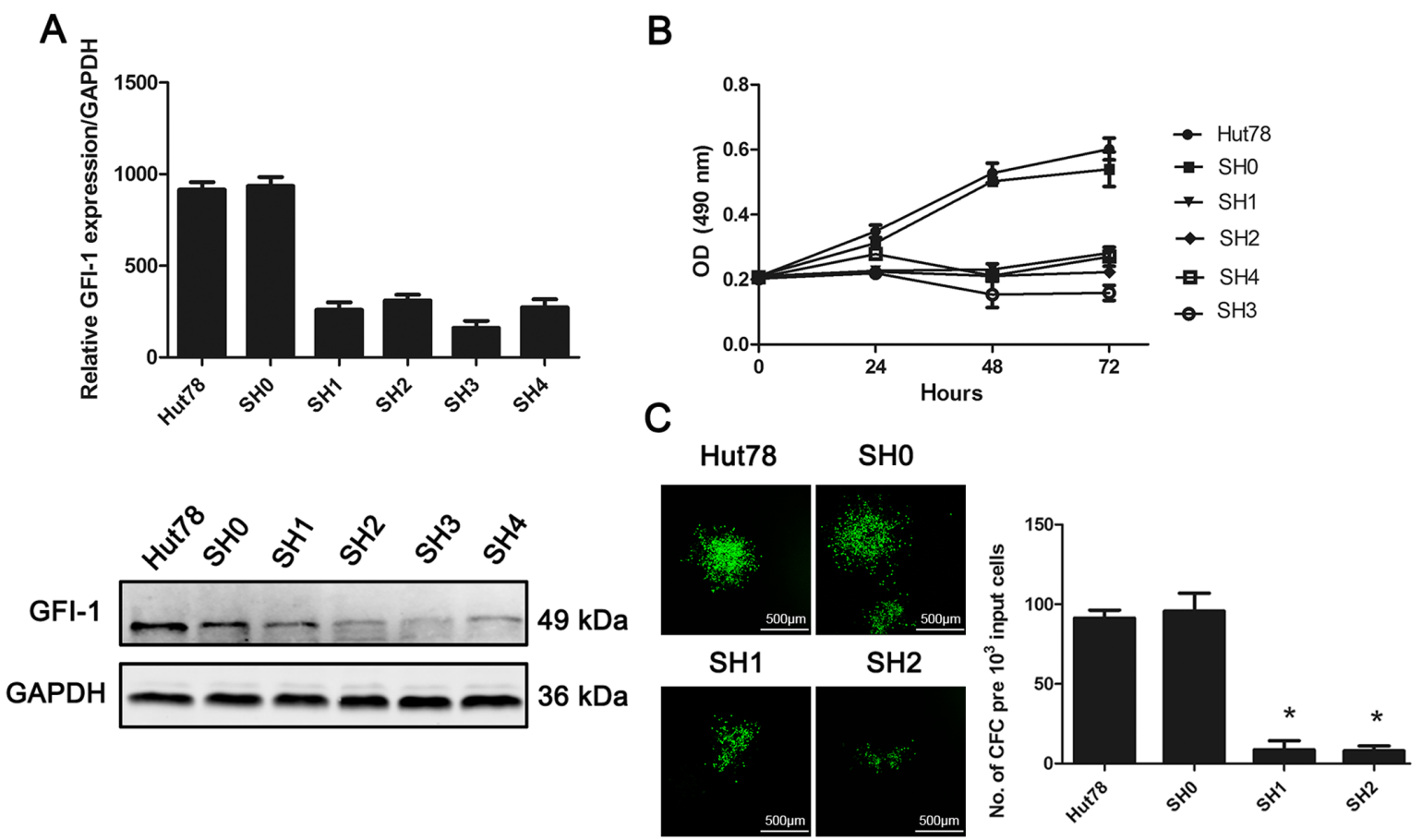

Figure 3. Effects of decreased GFI-1 expression on the cell growth and colony-forming ability of the CTCL Hut-78 cell line. (A) Suppression of GFI-1 mRNA expression in Hut-78 cells by lentiviral transduction with four independent shRNA sequences (SHI, SH2, SH3 and SH4), with non-silencing scrambled shRNA (SH0) used as the control. (B) Inhibition of cell growth in Hut-78 cells following GFI-1 suppression as measured by MTS assay. (C) Suppression of clonal proliferation in Hut-78 cells following GFI-1 suppression as measured by CFC assay. Magnification, 200x. "P<0.05. GFI-1, growth factor independence-1; sh, short hairpin RNA; OD, optical density.

Effect of GFI-1-knockdown on cell proliferation and colony-forming ability of the CTCL Hut-78 cell line. In order to study the role of GFI-1 in the development of MF, lentivirus-mediated RNAi technology was used to inhibit the expression of GFI-1 in the CTCL-derived cell line, Hut-78 (Fig. 3). The expression of GFI-1 in Hut-78 cells transfected with four shRNA sequences (SH1-4) was significantly decreased, and the difference was statistically significant compared with the untransfected group and the scramble transfected shRNA cells $(\mathrm{SH} 0)(\mathrm{P}<0.05)$. An MTS-based cell viability assay was used to assess the proliferation of Hut-78 cells following GFI-1-knockdown. Knockdown of GFI-1 expression resulted in significant inhibition of cell proliferation at 48 and $72 \mathrm{~h}$, compared with the control and SH0 groups (Fig. 2; P<0.05). Colony formation assays were used to determine the in vitro proliferation of cells following GFI-1-knockdown. With the decrease in GFI-1 gene expression, the ability of cells to form colonies in vitro was significantly decreased, compared with the control and SH0 groups $(\mathrm{P}<0.05)$.

Effects of decreased GFI-1 expression on cell cycle progression and spontaneous apoptosis. In order to further analyze the possible mechanisms by which cell proliferation is inhibited following knockdown of GFI-1, the cell cycle distribution was determined using flow cytometry and PI staining. The proportion of cells in the $\mathrm{G}_{0} / \mathrm{G}_{1}$ phase increased significantly, and the proportion of cells in the $G_{2} / M$ phase decreased significantly compared with the control group $(\mathrm{P}<0.05)$, which demonstrated that knockdown of the GFI-1 gene leads to $\mathrm{G}_{1}$ cell-cycle arrest. The apoptosis of cells was also studied using flow cytometry with Annexin V-PE/7AAD staining (Fig. 4). The proportion of apoptotic cells was significantly increased following GFI-1-knockdown, compared with the control group $(\mathrm{P}<0.05)$. These results indicated that GFI-1 knockdown-induced cell growth inhibition was caused by simultaneous G1 cell-cycle arrest and initiation of apoptosis.

GFI-1 specific-knockdown results in upregulation of P21, Bax and Caspase-3, as well as downregulation of CDK2 expression. In order to further study the possible molecular mechanisms that lead to cell cycle arrest and apoptosis following GFI-1-knockdown, lentivirus-transfected cells (SH1 and SH2) were used for transcriptome analysis, with non-transfected cells (Hut-78) and scramble shRNA-transfected cells (SH0) as the controls. The results demonstrated that Hut-78 cells with decreased GFI-1 expression exhibited numerous changes in the expression of genes (Fig. 5). Based on the criteria of a fold-change $>2$ and $\mathrm{P}<0.05$, 39 genes were found to be differentially expressed in the SH1 and SH2 cells, compared with the SH0 and Hut-78 cells. Among these, Bax and Caspase-3 expression levels, both of which are associated with spontaneous apoptosis, were upregulated, while $P 21$ and $C D K 2$ expression levels, both of which are associated with cell cycle inhibition, were upregulated and downregulated, respectively, and this was further confirmed by RT-qPCR and western blotting.

GFI-1 inhibits P21 transcriptional expression by directly binding to P21 and regulates its expression. Luciferase reporter assays were used to determine whether GFI- 1 directly regulates the transcription of $P 21$ in Hut-78 cells. To begin with, it was predicted that the only GFI- 1 binding site on the $P 21$ promoter was located within the region -884 to -860 (Fig. 5A) 


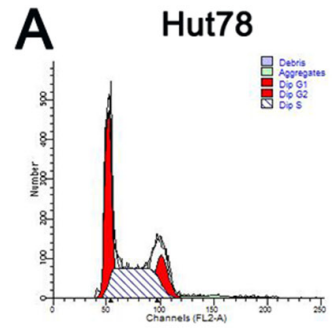

$\mathrm{SH} 1$

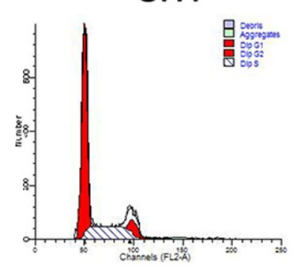

B

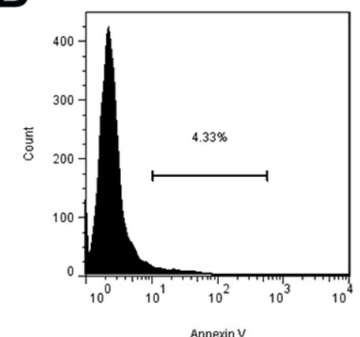

SH1

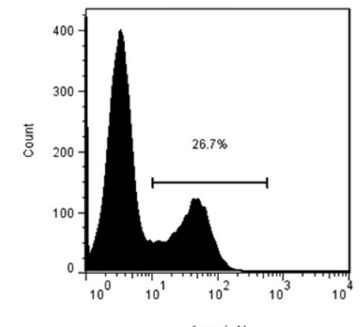

SHO

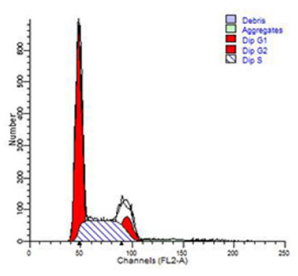

$\mathrm{SH} 2$

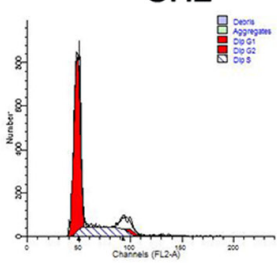

$\mathrm{SHO}$

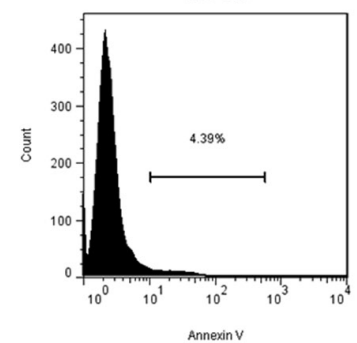

$\mathrm{SH} 2$

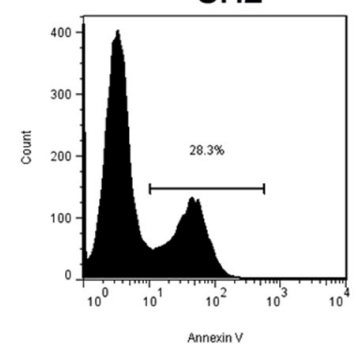

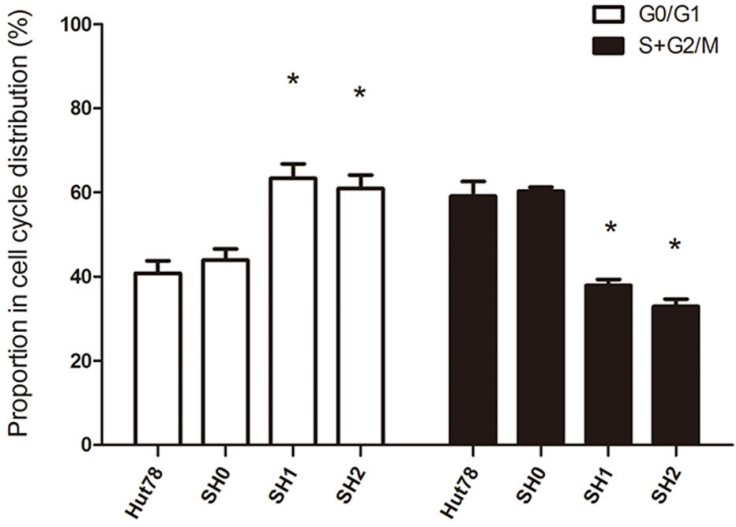

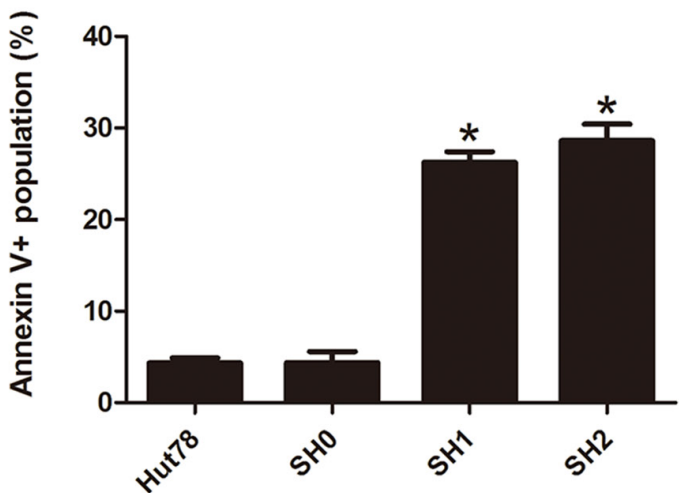

Figure 4. Effects of decreased GFI-1 expression on cell cycle and spontaneous apoptosis. (A) Increase in the G0/G1 population and decrease in the S and G2/M populations were observed in Hut-78 cells with GFI-1 silencing via PI cell-cycle analysis. (B) The lentiviral-transduced cells revealed an increase in Annexin V+ in GFI-1-silenced cells, which indicates increased cell apoptosis. SH1, SH2, SH3 and SH4 cells with four independent hairpins against GFI-1. SH0 cells transduced with scrambled shRNA served as the control. "P<0.05. GFI-1, growth factor independence-1; sh, short hairpin RNA.

using two different transcription factor binding analysis databases (MatInspector and JASPAR CORE). The $P 21$ promoter from $-1,148$ to +247 was cloned and ligated into a luciferase reporter vector, as well as two different promoter mutants with the key GFI-1 binding motif AGAT progressively mutated to CGCT or CACC (Fig. 6A). Dual-luciferase assays in Hut-78 cells revealed a dose-dependent increase in luciferase activity with the mutated promoters, indicating an inhibitory effect of GFI- 1 binding on $P 21$ transcription (Fig. 6B). These results demonstrated that GFI-1 inhibits $P 21$ expression by directly binding to a specific locus in the $P 21$ promoter and negatively regulating its transcription.

\section{Discussion}

The lack of MF treatment options is associated with the relatively poor understanding of the pathogenesis of the disease. Previous studies have demonstrated that MF is derived from skin-homing mature memory T-cells with cerebriform nuclei

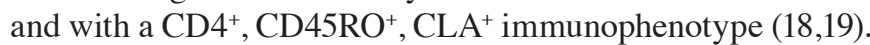
However, the mechanisms underlying the development and progression of tumor clonal hyperplasia in these cells remains unknown. Recent studies have reported that the aggregation of tumor cells in MF primarily depends on their resistance to induction of apoptosis, and this also explains the resistance of MF to conventional chemotherapeutic approaches $(20,21)$. However, the specific mechanism by which MF evades apoptosis is unclear. At present, due to the difficulty in obtaining purified MF cells in patients with skin lesions, research on the pathogenesis of MF is very limited. However, pathogenesis in vitro has been more extensively investigated in cultured CTCL cell lines. Upregulation of PAK1 and TOX $(22,23)$, dysregulated expression of AHI-1 and BCL11B (24,25), downregulation in SATB1 expression (15), and lack of Caspase activation have been associated with defects in apoptosis and the cell cycle in CTCL cell lines (26). 
A
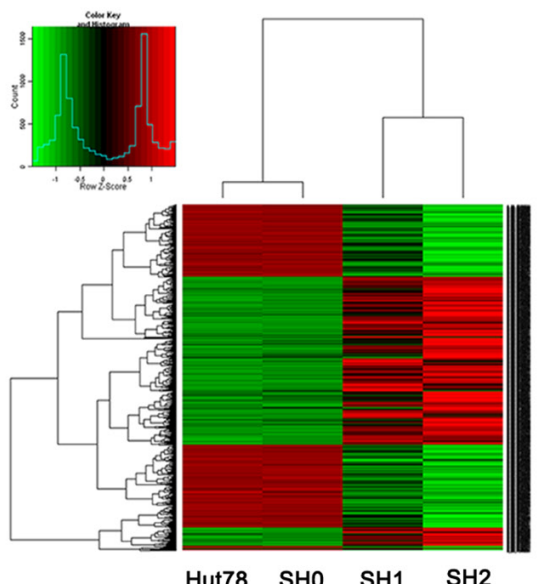

Hut78 SHO SH1 SH2
B
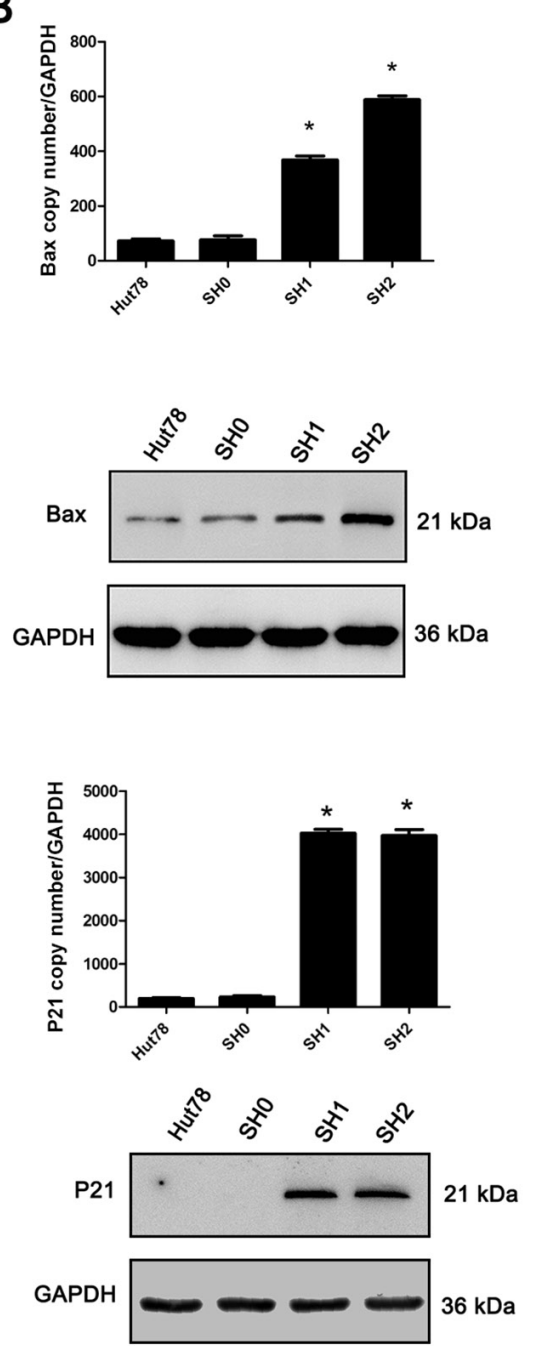
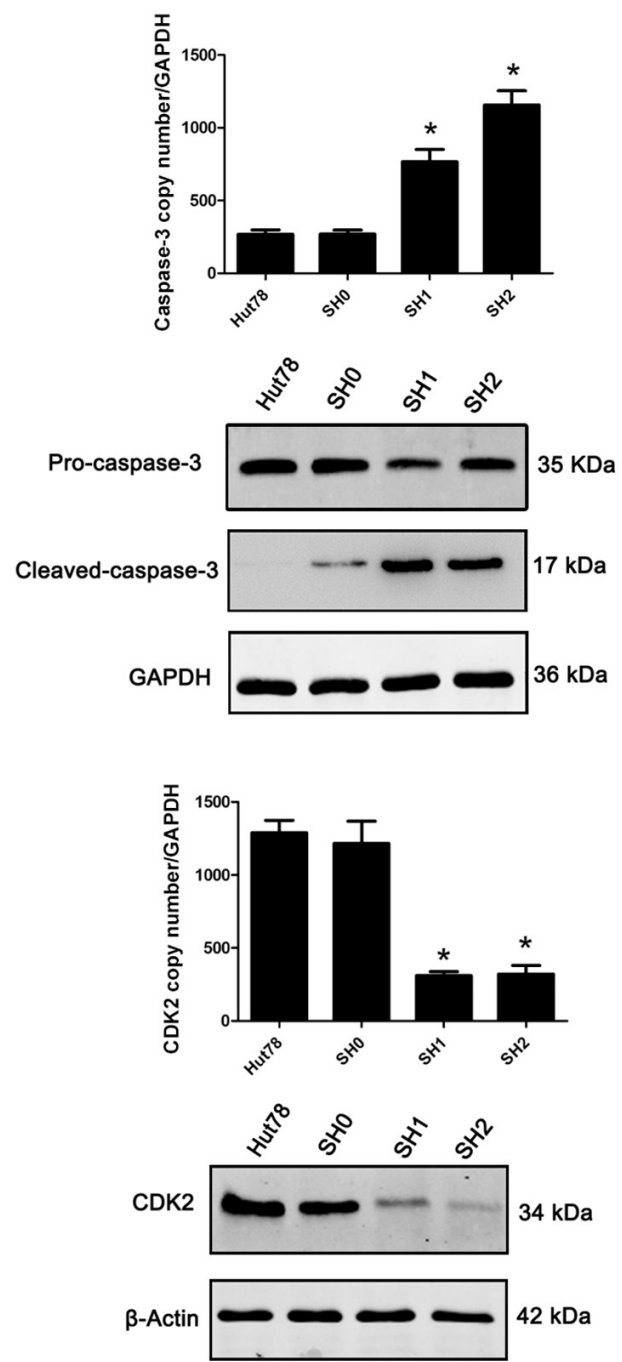

Figure 5. GFI-1-specific knockdown causes upregulation of P21, Bax and Caspase-3, and downregulation of CDK2 expression. (A) Hierarchical unsupervised clustering of the numerous genes, which clearly demonstrates a separation between lentivirus-transfected cells (SH1, SH2) and Hut78, SH0 cells. (B) mRNA expression levels of Bax, Caspase-3 and P21 were significantly higher in the GFI-1-silenced Hut-78 cells. mRNA expression levels of CDK2 were significantly decreased in the GFI-1-silenced Hut-78 cells. The aforementioned gene expression was confirmed by western blotting. " $\mathrm{P}<0.05$. GFI-1, growth factor independence-1; sh, short hairpin RNA.
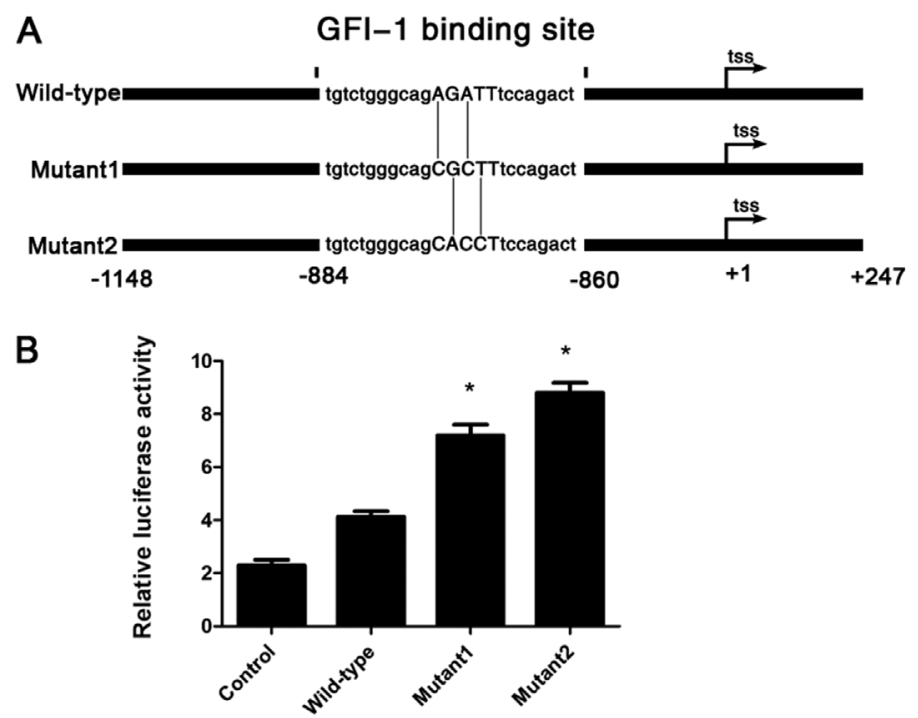

Figure 6. SATB1 binds to $P 21$ promoter and regulates its transcription. (A) The $P 21$ promoter (wild-type) and its mutants with deficient $G F I$ - 1 consensus binding site are shown schematically. (B) Dual-luciferase assay demonstrated that the luciferase activity of the $P 21$ promoter mutants were significantly higher than that of wide-type in Hut-78 cells. ${ }^{*} \mathrm{P}<0.05$. GFI-1, growth factor independence- 1. 
The present study demonstrated that the expression of GFI-1 protein in the tissues of patients with MF was significantly higher than in the tissues of patients with benign inflammation. Based on this result, it was further demonstrated that the specific knockdown of GFI-1 expression in the CTCL-derived Hut-78 cell line, significantly decreased the proliferation and clonal proliferation of these cells in vitro. Additionally, the cell cycle was inhibited and apoptosis was increased. Finally, GFI-1-knockdown resulted in upregulation of the apoptosis-related genes, Bax and Caspase-3, and simultaneously resulted in upregulation of the cell cycle-related gene P21, as well as downregulation of CDK2. The present study also aimed to detect the proliferation and apoptosis of normal peripheral blood T cells following GFI-1 gene expression being decreased. However, due to the relatively small number of cells obtained compared with the Hut78 cell line, it was challenging to transfect normal $\mathrm{T}$ cells. The majority of the cells died and the experiment was not possible to be carried out.

Grimes et al (27) demonstrated that in acute T-cell leukemia cell lines, increased expression of GFI-1 can reverse the cell cycle arrest caused by IL-2 deficiency, which resulted in increased clonal proliferation of tumor cells. Furthermore, it was further demonstrated that the SNAG domain in the GFI-1 protein possessed suppressor activity, which may lead to a decrease in the expression of associated genes that inhibit cell proliferation, leading to T-cell activation and tumor progression. Duan et al (28) demonstrated that GFI-1 inhibits P21 expression by recruiting the methyltransferase G9a and histone deacetylase 1 to the promoter of P21, leading to the progression of the cell cycle. P21 is a very important negative regulator in the cell cycle. It inhibits the progression of the cell cycle by inhibiting the activity of CDK1 and CDK2, which leads to the inhibition of cell growth $(29,30)$. Previous studies have demonstrated that P21 gene-knockout mice exhibit significantly increased susceptibility to formation of spontaneous tumors (31), and thus the occurrence of most types of tumors, including colon cancer, cervical cancer and small cell lung cancer, and this was correlated with the significantly decreased expression of P21 (32). The present study demonstrated that specific knockdown of GFI-1 expression may lead to inhibition of Hut-78 cell proliferation and clonal proliferation in vitro. Additionally, knockdown of GFI-1 resulted in increased expression of the cell cycle-related gene P21 and decreased expression of CDK2. Additionally, direct transcriptional repression of $P 21$ by $G F I-1$ was demonstrated in the luciferase assays. Based on the previous studies and the results of the present study, it was hypothesized that the inhibition of proliferation may be achieved through cell cycle inhibition, and GFI-1 may complete the inhibition of the Hut-78 cell cycle by regulating the P21-CDK2 pathway, and then inhibiting cell proliferation.

Previously, GFI-1, as a proto-oncoprotein, was revealed to directly inhibit the expression of pro-apoptotic regulators Bax and Bak, resulting in increased occurrence of T-cell-related tumors, and the GFI-1-mediated repression was direct and dependent on several GFI-1-binding sites in the p53-inducible Bax promoter (33). The present study demonstrated that knockdown of GFI-1 resulted in a significant increase in spontaneous apoptosis of Hut-78 cells in vitro. Additionally, knockdown led to upregulated expression of the pro-apoptotic factor Bax and an increase in the expression of the apoptotic pathway core protein Caspase-3. Therefore, the decreased expression of GFI-1 resulted in increased spontaneous apoptosis of cells via activation of the pro-apoptotic gene, Bax.

In conclusion, the results of the present study demonstrated that the abnormally high expression of GFI-1 in patients with MF serves an important role in the occurrence and development of disease. The abnormally high expression of GFI-1 may cause changes in the P21-CDK2 signaling pathway of epidermal T-cells, which leads to the uncontrolled proliferation of T-cells, and which also causes the T-cells to resist spontaneous apoptosis, through the inhibition of the pro-apoptotic factor Bax, leading to the formation of malignantly cloned T-cells. These results provided novel molecular insights into MF and may assist in identifying novel therapeutic targets for management of this disease.

\section{Acknowledgements}

Not applicable.

\section{Funding}

The present study was supported by grants from National Nature Science Foundation of China [grant nos. 81402259 (GXG) and 81972560 (ZCL)] and the Nature Science Foundation of Beijing [grant nos. 7163234 (GXG) and 7202231 ZCL)].

\section{Availability of data and materials}

The datasets used and/or analyzed during the current study are available from the corresponding author upon reasonable request.

\section{Authors' contributions}

$\mathrm{XG}$ conceived the experiments and designed the experiments. YW prepared the samples. XG performed the experiments. $\mathrm{CZ}$ analyzed the data. XG drafted the initial manuscript with input from all authors. YL performed the bioinformatics analysis and article revision. XG and YL confirmed the authenticity of all the raw data. All authors have read and approved the final manuscript.

\section{Ethics approval and consent to participate}

Written informed consent was obtained from all patients involved in the present study, which was performed according to the guidelines and with the approval of the Medical Ethics Committee of Aviation General Hospital (Beijing, China; approval no. 2014-41).

\section{Patient consent for publication}

Not applicable.

\section{Competing interests}

The authors declare that they have no competing interests. 


\section{References}

1. Wilcox RA: Cutaneous T-cell lymphoma: 2016 update on diagnosis, risk-stratification, and management. Am J Hematol 91: 151-165, 2016.

2. Goyal A, O'Leary D, Goyal K, Rubin N, Bohjanen K, Hordinsky M, Chen ST, Pongas G, Duncan LM and Lazaryan A: Increased risk of second primary hematologic and solid malignancies in patients with mycosis fungoides: A surveillance, epidemiology, and end results analysis. J Am Acad Dermatol 83: 404-411, 2020.

3. Zhang Y, Wang Y, Yu R, Huang Y, Su M, Xiao C, Martinka M, Dutz JP, Zhang X, Zheng Z and Zhou Y: Molecular markers of early-stage mycosis fungoides. J Invest Dermatol 132: 1698-1706, 2012.

4. Lansigan F, Choi J and Foss FM: Cutaneous T-cell lymphoma Hematol Oncol Clin North Am 22: 979-996, x, 2008.

5. Prince HM, Whittaker S and Hoppe RT: How I treat mycosis fungoides and Sezary syndrome. Blood 114: 4337-4353, 2009.

6. Zhang C, Richon V, Ni X, Talpur R and Duvic M: Selective induction of apoptosis by histone deacetylase inhibitor SAHA in cutaneous T-cell lymphoma cells: Relevance to mechanism of therapeutic action. J Invest Dermatol 125: 1045-1052, 2005

7. Willemze R, Jaffe ES, Burg G, Cerroni L, Berti E, Swerdlow SH, Ralfkiaer E, Chimenti S, Diaz-Perez JL, Duncan LM, et al: WHO-EORTC classification for cutaneous lymphomas. Blood 105: 3768-3785, 2005.

8. Hock H, Hamblen MJ, Rooke HM, Traver D, Bronson RT, Cameron S and Orkin SH: Intrinsic requirement for zinc finger transcription factor Gfi-1 in neutrophil differentiation. Immunity 18: 109-120, 2003

9. Yucel R, Karsunky H, Klein-Hitpass L and Moroy T: The transcriptional repressor Gfil affects development of early, uncommitted c-Kit+ T cell progenitors and CD4/CD8 lineage decision in the thymus. J Exp Med 197: 831-844, 2003.

10. van der Meer LT, Jansen JH and van der Reijden BA: Gfil and Gfilb: Key regulators of hematopoiesis. Leukemia 24: 1834-1843, 2010.

11. Zhu J, Jankovic D, Grinberg A, Guo L and Paul WE: Gfi-1 plays an important role in IL-2-mediated Th2 cell expansion. Proc Natl Acad Sci USA 103: 18214-18219, 2006

12. Rodel B, Tavassoli K, Karsunky H, Schmidt T, Bachmann M, Schaper F, Heinrich P, Shuai K, Elsässer HP and Möröy T: The zinc finger protein Gfi-1 can enhance STAT3 signaling by interacting with the STAT3 inhibitor PIAS3. EMBO J 19: 5845-5855, 2000 .

13. Kazanjian A, Gross EA and Grimes HL: The growth factor independence-1 transcription factor: New functions and new insights. Crit Rev Oncol Hematol 59: 85-97, 2006.

14. Zhou LL, Zhao Y, Ringrose A, DeGeer D, Kennah E, Lin AE, Sheng G, Li XJ, Turhan A and Jiang X: AHI-1 interacts with BCR-ABL and modulates BCR-ABL transforming activity and imatinib response of CML stem/progenitor cells. J Exp Med 205: 2657-2671, 2008

15. Wang Y, Su M, Zhou LL, Tu P, Zhang X, Jiang X and Zhou Y: Deficiency of SATB1 expression in Sezary cells causes apoptosis resistance by regulating FasL/CD95L transcription. Blood 117: 3826-3835, 2011

16. Su MW, Dorocicz I, Dragowska WH, Ho V, Li G, Voss N, Gascoyne R and Zhou Y: Aberrant expression of T-plastin in Sezary cells. Cancer Res 63: 7122-7127, 2003.

17. Gu X, Wang Y, Zhang G, Li W and Tu P: Aberrant expression of BCL11B in mycosis fungoides and its potential role in interferon-induced apoptosis. J Dermatol 40: 596-605, 2013.
18. Campbell JJ, Clark RA, Watanabe R and Kupper TS: Sezary syndrome and mycosis fungoides arise from distinct T-cell subsets: A biologic rationale for their distinct clinical behaviors. Blood 116: 767-771, 2010.

19. van Doorn R, van Kester MS, Dijkman R, Vermeer MH, Mulder AA, Szuhai K, Knijnenburg J, Boer JM, Willemze R and Tensen CP: Oncogenomic analysis of mycosis fungoides reveals major differences with Sezary syndrome. Blood 113: 127-136, 2009.

20. Hwang ST, Janik JE, Jaffe ES and Wilson WH: Mycosis fungoides and Sezary syndrome. Lancet 371: 945-957, 2008.

21. Dummer R, Asagoe K, Cozzio A, Burg G, Doebbeling U, Golling P, Fujii K and Urosevic M: Recent advances in cutaneous lymphomas. J Dermatol Sci 48: 157-167, 2007.

22. Wang Y, Gu X, Li W, Zhang Q and Zhang C: PAK1 overexpression promotes cell proliferation in cutaneous $\mathrm{T}$ cell lymphoma via suppression of PUMA and p21. J Dermatol Sci 90: 60-67, 2018.

23. Huang Y, Litvinov IV, Wang Y, Su MW, Tu P, Jiang X, Kupper TS, Dutz JP, Sasseville D and Zhou Y: Thymocyte selection-associated high mobility group box gene (TOX) is aberrantly over-expressed in mycosis fungoides and correlates with poor prognosis. Oncotarget 5: 4418-4425, 2014.

24. Ringrose A, Zhou Y, Pang E, Zhou L, Lin AE, Sheng G, Li XJ, Weng A, Su MW, Pittelkow MR and Jiang X: Evidence for an oncogenic role of AHI-1 in Sezary syndrome, a leukemic variant of human cutaneous T-cell lymphomas. Leukemia 20: 1593-1601, 2006.

25. Fu W, Yi S, Qiu L, Sun J, Tu P and Wang Y: BCL11B-Mediated epigenetic repression is a crucial target for histone deacetylase inhibitors in cutaneous T-Cell lymphoma. J Invest Dermatol 137: 1523-1532, 2017.

26. Frei GM, Kremer M, Hanschmann KM, Krause S, Albeck M, Sredni B and Schnierle BS: Antitumour effects in mycosis fungoides of the immunomodulatory, tellurium-based compound, AS101. Br J Dermatol 158: 578-586, 2008

27. Grimes HL, Chan TO, Zweidler-McKay PA, Tong B and Tsichlis PN: The Gfi-1 proto-oncoprotein contains a novel transcriptional repressor domain, SNAG, and inhibits G1 arrest induced by interleukin- 2 withdrawal. Mol Cell Biol 16: 6263-6272, 1996

28. Duan Z, Zarebski A, Montoya-Durango D, Grimes HL and Horwitz M: Gfil coordinates epigenetic repression of 2 21Cip/WAF1 by recruitment of histone lysine methyltransferase G9a and histone deacetylase 1. Mol Cell Biol 25: 10338-10351, 2005.

29. Mandal M, Bandyopadhyay D, Goepfert TM and Kumar R: Interferon-induces expression of cyclin-dependent kinase-inhibitors p21WAF1 and p27Kip1 that prevent activation of cyclin-dependent kinase by CDK-activating kinase (CAK). Oncogene 16: 217-225, 1998.

30. Abbas T, Jha S, Sherman NE and Dutta A: Autocatalytic phosphorylation of CDK2 at the activating Thr160. Cell Cycle 6: 843-852, 2007.

31. Martin-Caballero J, Flores JM, Garcia-Palencia P and Serrano M: Tumor susceptibility of p21(Waf1/Cip1)-deficient mice. Cancer Res 61: 6234-6238, 2001.

32. Shiohara M, el-Deiry WS, Wada M, Nakamaki T, Takeuchi S, Yang R, Chen DL, Vogelstein B and Koeffler HP: Absence of WAF1 mutations in a variety of human malignancies. Blood 84 : 3781-3784, 1994.

33. Grimes HL, Gilks CB, Chan TO, Porter S and Tsichlis PN: The Gfi-1 protooncoprotein represses Bax expression and inhibits T-cell death. Proc Natl Acad Sci USA 93: 14569-14573, 1996.

This work is licensed under a Creative Commons Attribution-NonCommercial-NoDerivatives 4.0 International (CC BY-NC-ND 4.0) License. 